\title{
1 Microplastic ingestion in fish larvae in the western English Channel
}

2

3

5

6
Madeleine Steer ${ }^{a}$, Matthew Cole ${ }^{b}$, Richard C. Thompson ${ }^{c}$, Penelope K. Lindeque ${ }^{a^{*}}$

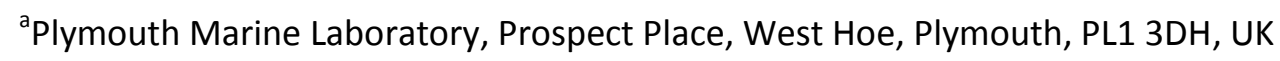

${ }^{b}$ College of Life and Environmental Sciences: Biosciences, University of Exeter, Geoffrey Pope, Stocker Road, Exeter, EX4 4QD, UK

${ }^{c}$ Marine Biology and Ecology Research Centre, School of Biological and Marine Sciences, University of Plymouth, Drake Circus, Plymouth, PL4 8AA, UK

*Corresponding author: Telephone: +44 (0)1752633415; Email: pkw@pml.ac.uk

\section{Abstract}

Microplastics have been documented in marine environments worldwide, where they pose a potential risk to biota. Environmental interactions between microplastics and lower trophic organisms are poorly understood. Coastal shelf seas are rich in productivity but also experience high levels of microplastic pollution. In these habitats, fish have an important ecological and economic role. In their early life stages, planktonic fish larvae are vulnerable to pollution, environmental stress and predation. Here we assess the occurrence of microplastic ingestion in wild fish larvae. Fish larvae and water samples were taken across three sites (10, 19 and $35 \mathrm{~km}$ from shore) in the western English Channel from April to June 2016. We identified 2.9\% of fish larvae ( $n=347$ ) had ingested microplastics, of which $66 \%$ were blue fibres; ingested microfibers closely resembled those identified within water samples. With distance from the coast, larval fish density increased significantly $(P<0.05)$, while waterborne microplastic concentrations $(P<0.01)$ and incidence of ingestion decreased. This study provides baseline ecological data illustrating the correlation between waterborne microplastics and the incidence of ingestion in fish larvae.

\section{CAPSULE:}

We identified $2.9 \%$ of fish larvae $(n=347)$ had ingested microplastics (predominantly fibres) in the western English Channel. Ingested microfibers closely resembled those identified in water samples. 


\section{Introduction}

Microplastic (microscopic plastic, $0.1 \mu \mathrm{m}-5 \mathrm{~mm}$ ) debris has emerged as a persistent environmental pollutant, recognised within the scientific and political community as a ubiquitous contaminant of global concern (Thompson et al., 2004). The increasing abundance and widespread distribution of microplastics has led to concerns over the risks posed to the health of organisms and ecosystem processes (Clark et al., 2016). Since the emergence of mass-produced plastics in the 1930s (BPF, 2017), production has increased annually, currently reaching in excess of 322 million tonnes per year globally (PlasticsEurope, 2016). Its durability, low cost and widespread application has made plastic a popular manufacturing material worldwide (Cole et al., 2011). These same characteristics make it difficult to dispose of, and once in the environment could be considered a persistent and potentially hazardous pollutant (Rochman et al., 2013a). Marine plastic debris stems from poor waste management and accidental losses from fishing, industry, shipping and tourism among other sources (Jambeck et al., 2015). Microplastic pollution originates from the photoxidative degradation and subsequent fragmentation of this larger debris (Jambeck et al., 2015), termed secondary microplastics, and the release of plastics manufactured to be of a microscopic size, such as exfoliates in cosmetics (Napper et al., 2015), termed primary microplastics. Microplastics in marine waters were first documented over forty years ago in the North Atlantic subtropical gyre (Carpenter, E. J., et al., 1972). Microplastics have since been found in a diverse range of marine ecosystems, including deep ocean sediments (Van Cauwenberghe et al., 2013) and Arctic waters (Lusher et al., 2015). Recent estimates suggest over 5.25 trillion items of floating plastic litter are polluting the world's oceans, of which the vast majority are microscopic in size (Eriksen et al., 2014).

Microplastic pollution poses a threat to marine biota through ingestion or entanglement (Wright et al., 2013b). Continuous fragmentation and degradation of microplastics in the marine environment produces a wide range of particle sizes (Enders et al., 2015), which can be ingested by an equally wide range of marine organisms, including the Humbolt squid (Braid et al., 2012), blue mussel and Pacific oyster (Van Cauwenberghe and Janssen, 2014), gooseneck barnacle (Goldstein and Goodwin, 2013), Norway lobster (Murray and Cowie, 2011), brown shrimp (Devriese et al., 2015), zooplankton (Desforges et al., 2015), harbour seal (Rebolledo et al., 2013) and green turtle (Tourinho et al., 2010). The overlap between microplastics and marine biota is predicted to be most pronounced in shelf sea regions (Clark et al., 2016), owing to high levels of biological productivity and high microplastic concentrations stemming from the proximity to terrestrial sources of pollution (e.g. rivers, estuaries, sewage outfalls) (Browne et al., 2011, Desforges et al., 2014). 
Zooplankton encompass a diverse group of planktonic animals, including the larval stages of vertebrates and invertebrates. Marine zooplankton predominantly inhabit surface waters when feeding, where microplastics are found in high abundance (Cozar et al., 2014), increasing the opportunity for them to ingest microplastics. Under laboratory conditions, zooplankton (e.g. copepods, urchin larvae, bivalve larvae, decapod larvae) have been observed to readily consume microplastics (Cole et al., 2013, Cole and Galloway, 2015, Cole et al., 2015, Nobre et al., 2015, Setala et al., 2014, Lee et al., 2013, Kaposi et al., 2014). Toxicity testing has highlighted the adverse physical (Wright et al., 2013a) and toxicological effects that microplastic exposure can have on marine biota (Ogonowski et al., 2016, Peda et al., 2016, Watts et al., 2016, Cole et al., 2015). Experiments using marine worms and zooplankton have demonstrated that microplastic ingestion can result in reduced feeding, increased mortality, decreased growth rates, decreased hatching success and reduced fecundity (Wright et al., 2013a, Cole et al., 2015). Marine zooplankton are a vital source of food for secondary consumers (e.g. fish, cetaceans), and, as such, may represent a route via which microplastics enter the food web, posing a risk to secondary producers, apex predators and potentially human health (Clark et al., 2016). Field observations detailing incidence of microplastic ingestion by organisms typically relate to larger organisms (e.g. squid, mussels, oysters, adult fish), owing to the constraints associated with collecting and processing samples (Lusher et al., 2017). Research by Desforges et al. (2014) on zooplankton communities in the North East Pacific has shown microplastic ingestion ratios of 1 in 17 copepods (Neocalanus cristatus), and 1 in 34 euphausiids (Euphausia pacifica), of which $50-68 \%$ were fibres. Microplastics have been further identified in zooplankton communities sampled from the South China Sea, with $70 \%$ of identified plastics being fibrous (Sun et al., 2016). Otherwise, very little is known about ingestion rates of microplastics in wild zooplankton and the type, source and distribution of plastic being ingested.

Fish stocks have considerable ecological and economic value. Global annual fisheries revenue fluctuates around USD 100 billion supporting about $12 \%$ of the world population, and providing 2.9 billion people with $20 \%$ of their animal protein (Lam et al., 2016). With over 30,000 species of fish worldwide, existing in all of the worlds marine habitats, their abundance and diversity has significant ecological importance for the food chain, nutrient cycling and ecosystem services (Worm et al., 2006). Ichthyoplanktonic studies show that unfished taxa account for the majority of fish larvae and contribute significantly to trophic food webs (Baran, 2002). Fish populations are vulnerable to a growing number of anthropogenic pressures, including overfishing, climate change and pollution, resulting in increased mortality and reduced fecundity. Incidence of microplastic consumption by adult fish has been widely reported for pelagic and demersal populations across the globe, including 
blue whiting (Micromesistius poutassou), red gurnard (Aspitrigla cuculus), john dory (Zeus faber) and dragonet (Callionymus lyra) (Lusher et al., 2013). However, there is currently no substantial published data regarding microplastic ingestion rates in fish larvae. Fish larvae play a pivotal role in marine food webs (Russell, 1976), and their health, development and survival is fundamental to the long-term sustainability of healthy fish populations. As such, data is urgently required to better assess the risks posed to fish larvae by microplastics in natura.

In this study we investigate the incidence of microplastic ingestion by fish larvae in the productive shelf-sea waters of the western English Channel, off the coast of Plymouth (UK). We look to test the hypotheses that: (1) microplastic concentrations increase with proximity to the coast; (2) fish larvae consume microplastic debris in their natural environment; and, (3) incidence of microplastic consumption is regulated by the abundance of larvae and the abundance of microplastics. Fish larvae and microplastics were collected via oblique tows, across three sites with varying distance from shore; microplastics were isolated using dissection and enzymatic digestion of samples.

\section{Methodology}

\subsection{Field sampling}

Field sampling was undertaken on board RV Plymouth Quest in the western English Channel off the coast of Plymouth (UK). Sampling was conducted at stations L4, L5 and E1 $(10 \mathrm{~km}, 19 \mathrm{~km}$ and $35 \mathrm{~km}$ from shore respectively), which are routinely sampled as part of the Western Channel Observatory (WCO; www.westernchannelobservatory.org.uk). The sampling sites spanned distances of 10-35 km from the city of Plymouth (Figure 1), accounting for habitats with a coastal (L4) and oceanic influence (E1); L5 was added as a reference site because it is a rocky reef known to be a favourable habitat for fish larvae. Eleven samples were collected between $11^{\text {th }}$ April 2016 and $21^{\text {st }}$ June 2016 across the three sites $(L 4, n=5 ; \mathrm{L} 5, n=3 ; \mathrm{E} 1, n=3)$. For each trawl, tow distance and maximal sample depths were recorded using GPS and a Suunto vyper dive computer respectively; maximum depths reached were on average $50 \mathrm{~m}$ at $\mathrm{L} 4$ and $\mathrm{L} 5$, and $65 \mathrm{~m}$ at E1. Fish larvae were collected using a 500 $\mu \mathrm{m}$ metal-framed net ( $1 \mathrm{~m}^{2}$ square aperture) towed for 20 minutes on an oblique tow. Following the trawl, larvae were passed through a $500 \mu \mathrm{m}$ sieve and rinsed with filtered $(0.22 \mu \mathrm{m})$ natural seawater. Subsequently, specimens were transferred into a $1 \mathrm{~L} \mathrm{Nalgene} \mathrm{bottle} \mathrm{and} \mathrm{preserved} \mathrm{in} 4 \%$ formalin. Microplastics were sampled using a $100 \mu \mathrm{m}$ WP2 net (47 cm diameter aperture), suspended below the net used for sampling the fish larvae. This concurrent sampling allowed for direct comparison of microplastics ingested by the fish larvae with 'prey-sized' microplastics in the 
137

surrounding water. Following sampling, the WP2 net was rinsed with filtered seawater and the sample poured through a $100 \mu \mathrm{m}$ mesh; samples were immediately sealed and subsequently stored in a foil envelope in a $-80^{\circ} \mathrm{C}$ freezer prior to analysis. Control measures included collection of procedural blanks using filtered sea water, and sampling of boat paint for Fourier Transform Infrared Spectroscopy (FT-IR) analysis to ensure false positives were avoided in the plastics count.

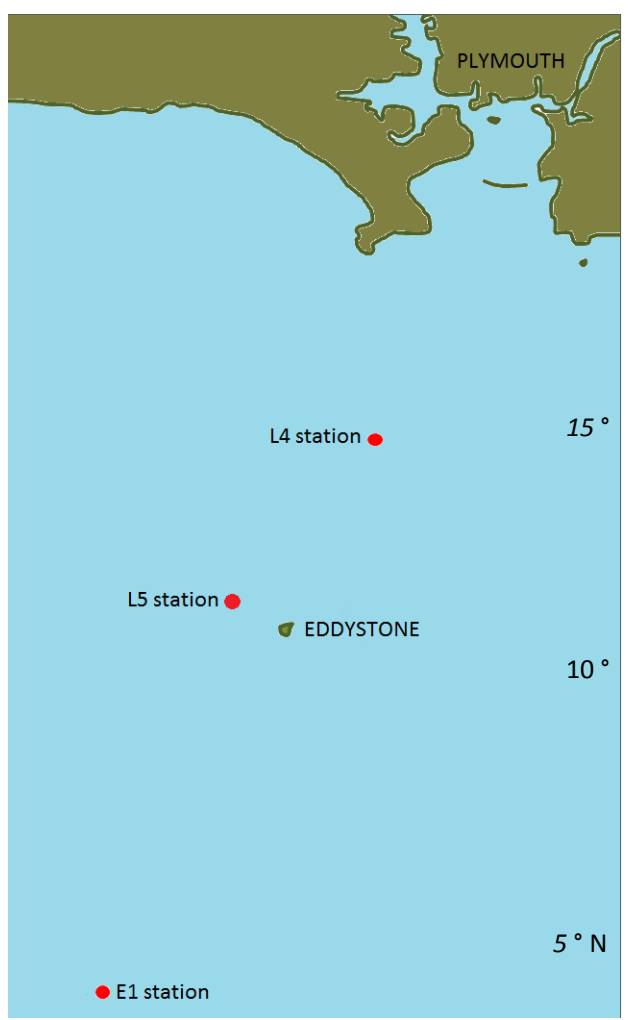

Figure 1. Sampling sites located in the western English Channel. E1: 35 km offshore Plymouth; L5: 19 km offshore; L4: 10 $\mathrm{km}$ offshore.

\subsection{Fish larvae}

Fish larvae were isolated by screening the formalin preserved net samples through a $2000 \mu \mathrm{m}$ sieve. Specimens were rinsed thoroughly, and the $2000 \mu \mathrm{m}$ sieve placed in a tray of water to float the sample inside the sieve. Fish larvae $>10 \mathrm{~mm}$ were handpicked and placed into a covered beaker containing ultrapure water. The total number of fish larvae per sample was recorded, and fish larvae density (individuals $\mathrm{m}^{-3}$ ) calculated using the net dimensions, tow length and depth, and a net efficiency of 85\% (Southward, A. J., 1970). All fish larvae larger than $9 \mathrm{~mm}$ were identified to species level. 


\subsection{Microplastic ingestion in marine fish larvae}

Fish larvae were assessed under a dissection microscope (Wild Heerbruug Switerland M5-49361; 6x50x magnification) with gooseneck lighting (Schott KL1500 LCD). Individual fish larvae were placed in a Petri dish $(50 \mathrm{~mm}$ ) on a polycarbonate filter paper (Whatman cyclopore, $47 \mathrm{~mm}, 10 \mu \mathrm{m}$ ) and identified to species level (Russell, 1976, Munk and Nielsen, 2005). Larval length was recorded, however, accurate aging was not possible owing to variability in growth rates (Russell, 1976). Prior to dissection, larvae were checked for microplastics adhered to external surfaces. The jaw, oesophagus, stomach and intestines were removed using fine tweezers and needle. The digestive tract was inspected for microplastic particles in accordance with the Norén (2007) protocol: (1) no cellular or organic structures are visible; (2) if the particle is a fibre, it should be equally thick, not taper towards the ends and have a three-dimensional bending; (3) homogeneously coloured/clear particles. If a suspect particle was found, the particle, guts and fish were photographed and the particle sized (Olympus SZX16 Stereo Microscope with Canon DS126271 camera). A diamond compression cell (Specac DC2; $2 \mathrm{~mm}$ diameter) was used to prepare suspect microplastics prior to FT-IR analysis; FT-IR was conducted using a Brucker Vertex 70 micro FT-IR coupled with a Bruker Hyperion 1000 microscope. Spectra were assessed using Bruker Opus 7.5 software.

\subsection{Waterborne microplastics}

Waterborne microplastic samples were removed from storage, and then freeze dried for 72 hours (Scanvac CoolSafe freeze drier). Desiccated samples were put through an enzymatic digestion protocol adapted from Cole et al. (2014); here, we used the enzymes Proteinase $\mathrm{K}$ and cellulase to remove biotic material, whilst retaining anthropogenic and inorganic material for inspection and characterisation. In brief: the total weight of each sample was recorded, and if the sample weighed more than $0.5 \mathrm{~g}$, then a $0.5 \mathrm{~g}$ subsample was taken. Each sample was placed in $30 \mathrm{~mL}$ of homogenising solution, physically homogenised and incubated at $50^{\circ} \mathrm{C}$ for 30 minutes. Next, $1 \mathrm{~mL}$ of $20 \mathrm{mg} \mathrm{mL}^{-1}$ Proteinase $\mathrm{K}$ was added and incubated at $50^{\circ} \mathrm{C}$ overnight. Cellulase was introduced to the protocol in order to further breakdown any remaining phytoplankton and organic material; $1 \mathrm{~mL}$ of $40 \mathrm{mg} \mathrm{mL}^{-1}$ cellulase was added and the maintained at $4^{\circ} \mathrm{C}$ overnight to optimise enzymatic degradation. Finally, $8.5 \mathrm{~mL}$ of $5 \mathrm{M}$ sodium perchlorate was added, the sample physically homogenised and placed in a water bath at $60^{\circ} \mathrm{C}$ for 30 minutes. Digested samples were then vacuum filtered (Whatman cyclopore, $47 \mathrm{~mm}, 10 \mu \mathrm{m}$ ) and rinsed thoroughly with ultrapure water. Filters were analysed on an Olympus SZX16 Stereo Microscope (110 x magnification) and microplastics identified per the Norén (2007) protocol (see previous section). Suspect microplastics were quantified and characterised (shape and colour) and a randomly selected subsample of fibres 
and particles were retained for sizing $(n=696)$ and FT-IR analysis $(n=90)$, carried-out as described above. Waterborne microplastic concentrations (microplastics $\mathrm{m}^{-3}$ ) were calculated using the net dimensions, tow length and depth, and a WP2 net efficiency of 95\% (UNESCO, 1968).

\subsection{Incidence of ingestion and encounter rate}

Individual fish dissections allowed for 'incidence of ingestion' (number of fish that ingested microplastic / total number fish dissected) to be calculated. For comparability with other field studies, where analysis of smaller zooplankton necessitated bulk digestions (Sun et al., 2016, Desforges et al., 2015), 'encounter rate' (total number of microplastic particles ingested / number fish dissected) was also calculated.

\subsection{Contamination controls}

Great care was taken during this study to minimise microplastic contamination, with controls set in place for every stage of the field and laboratory work. Cotton clothing was worn wherever possible and a white cotton lab coat was worn during laboratory work. The work station was cleaned before use and lids were placed over samples wherever possible. All Petri dishes and Eppendorfs were sealed for storage between sessions. Dissection instruments were soaked in ethanol between samples to avoid cross contamination. Two procedural blanks, using filtered sea water, were collected on board the RV Plymouth Quest, and subsequently run through the entire laboratory procedure. During the fish dissections and microscopy, Petri dishes containing dampened polycarbonate filters (Whatman cyclopore, $47 \mathrm{~mm}, 10 \mu \mathrm{m}$; pre-screened under microscope for manufacturing debris) were setup to account for airborne contamination (Lusher et al., 2017); any suspect microplastics presented on the filter was recorded and accounted for in the data. Finally, the FT-IR results were used to adjust the plastic count according to the percent success in identification of plastics versus organic material.

.

.




\subsection{Fish larvae}

229

Fish larvae concentrations (individuals $\mathrm{m}^{-3}$ ) significantly increased with distance from coast (ANOVA, $P<0.05$; Figure $2 \mathrm{~A}$ ), with population densities ranging 0.10 fish larvae $\mathrm{m}^{-3}$ at $L 4,10 \mathrm{~km}$ from Plymouth, to 0.70 fish larvae $\mathrm{m}^{-3}$ at E1, $35 \mathrm{~km}$ offshore from Plymouth (Table 1).

Table 1. Mean fish larvae data across sites in the western English Channel.

\begin{tabular}{|c|c|c|c|}
\hline Site & L4 & L5 & E1 \\
\hline Distance from Plymouth (km) & 10 & 19 & 35 \\
\hline Number of fish larvae sampled $(n)$ & 135 & 75 & 137 \\
\hline Fish larvae concentration (mean individuals $\mathrm{m}^{-3}$ ) & 0.10 & 0.12 & 0.70 \\
\hline Incidence of ingestion (no. fish that ingested microplastic / no. fish dissected) & $3.7 \%$ & $5.3 \%$ & $0.7 \%$ \\
\hline Encounter rate (no. microplastic particles ingested / no. fish dissected) & $5.2 \%$ & $5.3 \%$ & $0.7 \%$ \\
\hline Waterborne microplastic concentration (mean number $\mathrm{m}^{-3}$ ) & 2.43 & 0.96 & 0.79 \\
\hline Ratio fish larvae : microplastic $\left(\mathrm{m}^{-3}\right)$ & $1: 27$ & $1: 9$ & $1: 1$ \\
\hline
\end{tabular}

A

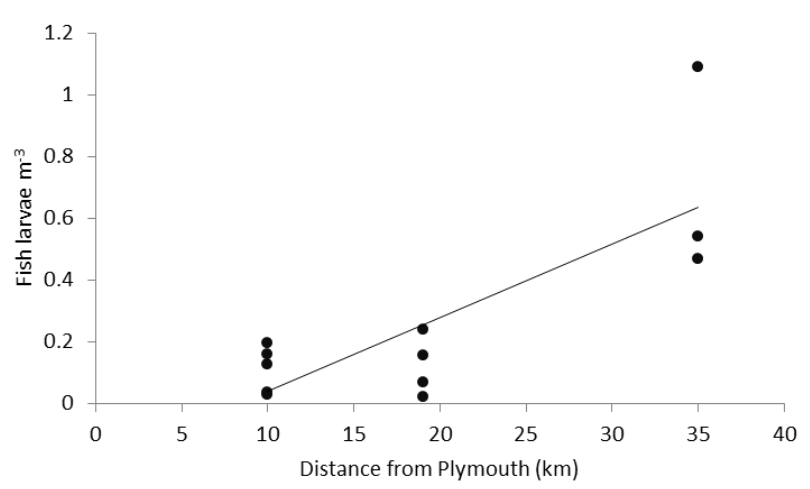

B

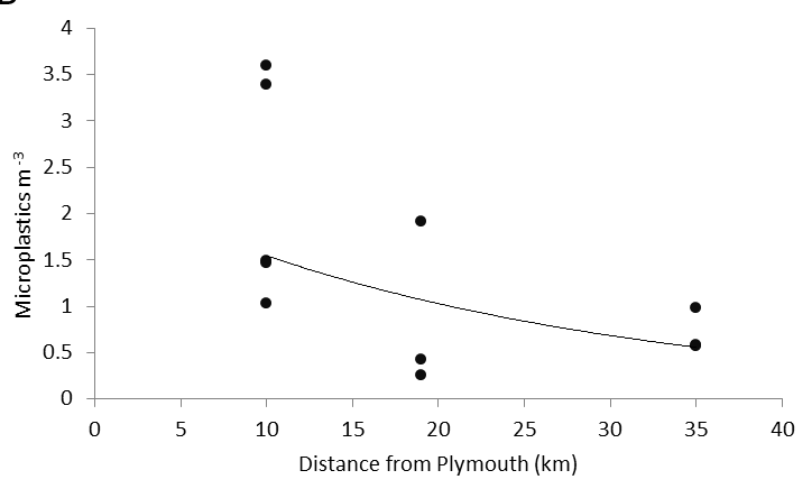

Figure 2. Relationships between distance from Plymouth $(\mathrm{km})$ and: (A) Fish larvae density (individuals $\mathrm{m}^{-3}$ ), linear regression (black line), $R^{2}=0.63, P<0.05, n=12$; (B) Waterborne microplastics concentrations (microplastics $\mathrm{m}^{-3}$ ), exponential regression (black line), $\mathrm{R}^{2}=0.84, P<0.01, n=11$. 


\subsection{Microplastic ingestion in marine fish larvae}

243 A total of 347 fish larvae across 23 species were examined for microplastic ingestion, with 10 larvae $244(2.9 \%)$ confirmed to contain microplastic particles in their digestive tract. Ingestion was observed in 245 five species (Table 2A): whiting (Merlangius merlangus; $n=5$; Figure 3a), thickback sole (Microchirus variegatus; $n=2$; Fig 3b), poor cod (Trisopterus minutus; $n=1$ ), common dragonet (Callionymus lyra; $n=1$; Figure 3c), and European eel (Anguilla anguilla; $n=1$ ). Encounter rates generally reflected the species composition of the net catches (Table 2B) with the exception of thickback sole and the European eel elver. At Station L4 thick back sole made up just over $2 \%$ of the species composition of fish larvae over $9 \mathrm{~mm}$ in length and yet showed the highest encounter rate, however, this trend was not repeated at Stations L5 or E1. Fish larvae containing ingested microplastics averaged $10 \pm 2.38$ $\mathrm{mm}$ in length (excluding the $1240 \mathrm{~mm}$ European eel larvae), indicating they were likely to be no more than two months old (Russell, 1976). The microplastics ingested by fish larvae consisted of blue or red fibres (83\%) and blue fragments (17\%); fragments ranged from 50-100 $\mu \mathrm{m}$ in size, with fibres ranging from 100-1100 $\mu \mathrm{m}$ in length. FT-IR analysis confirmed that ingested particles consisted of either nylon, a polyester-polyamide composite or synthetic bioplastic (Rayon). Two fish larvae contained two particles, whilst eight larvae contained just one each.

Table 2. (A) Fish larvae $(n=10)$ containing microplastic debris, detailing numbers, type, colour, polymer and size of ingested microplastic, (B) species composition of all fish caught over $9 \mathrm{~mm}$ in size (excluding sprat) and encounter rate.

\begin{tabular}{|l|l|l|l|l|}
\hline A & Site & Characterisation & Polymer & Size $(\mu \mathrm{m})$ \\
\hline Common dragonet & L4 & 2 blue fibres & Nylon & 220,230 \\
\hline European eel & L5 & 1 blue fragment & Polyamide-polypropylene & $100 \times 50$ \\
\hline Poor cod & L4 & 1 blue fragment & Unknown* & $50 \times 50$ \\
\hline Thickback sole & L4 & 1 red fibre & Rayon & 270 \\
& L4 & 2 blue fibres & Unknown* & 250,250 \\
\hline \multirow{2}{*}{ Whiting } & L4 & 1 blue fibre & Rayon & 300 \\
& L5 & 1 blue fibre & Rayon & 310 \\
& L5 & 1 blue fibre & Rayon & 450 \\
& L5 & 1 red fibre & Rayon & 1100 \\
& E1 & 1 blue fibre & Rayon (elastic ) & 100 \\
\hline
\end{tabular}


B

\begin{tabular}{|l|c|c|c|c|c|c|}
\hline & \multicolumn{2}{|c|}{ L4 (n=197) } & \multicolumn{2}{c|}{ L5 (n=67) } & \multicolumn{2}{c|}{ E1 (n=198) } \\
\hline Species & \% composition & encounter rate \% & \% composition & encounter rate \% & \% composition & encounter rate \% \\
\hline Whiting & 31 & 0.5 & 50.3 & 4.5 & 42.6 & 0.51 \\
\hline Poor Cod & 17.3 & 0.5 & 4.3 & 0 & 8 & 0 \\
\hline Thickback Sole & 2.1 & 1.5 & 2 & 0 & 5 & 0 \\
\hline Common Drag & 13.9 & 1 & 22.6 & 0 & 21.8 & 0 \\
\hline European eel & 0 & 0 & 1.5 & 1.5 & 0 & 0 \\
\hline Other & 35.7 & 0 & 19.3 & 0 & 22.6 & 0 \\
\hline
\end{tabular}
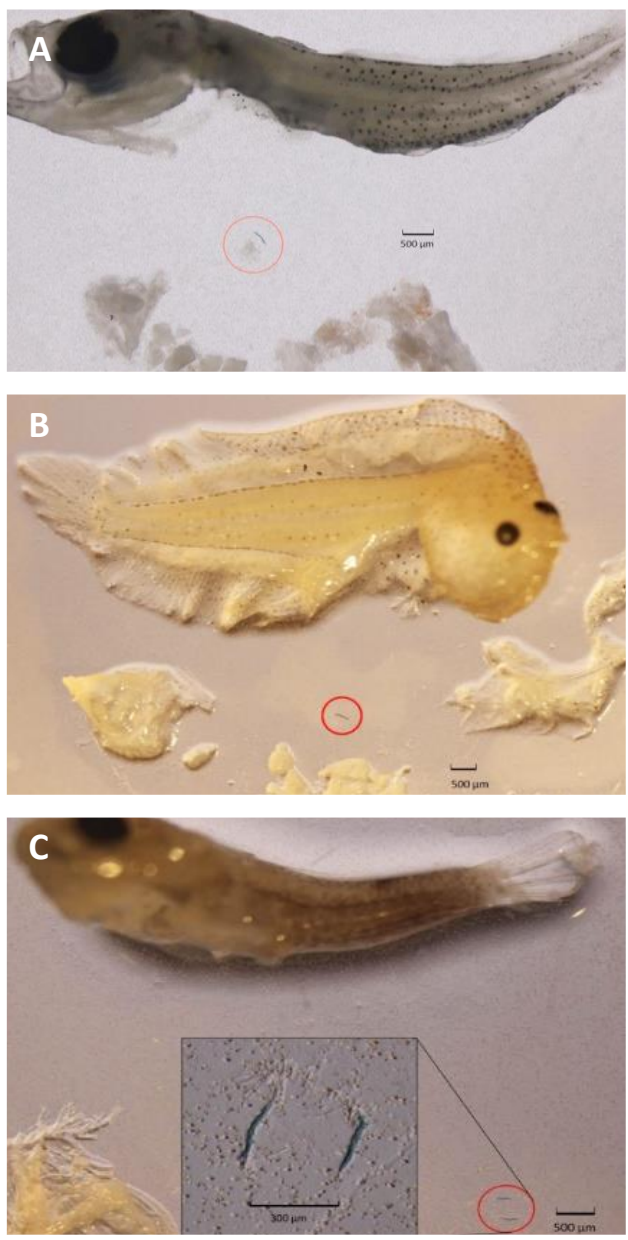

Figure 3. Photographs of dissected fish larvae that had ingested microplastics (circled), viewed under an Olympus SZX16 Stereo Microscope. (A) Whiting (12 mm in length) with $310 \mu \mathrm{m}$ rayon fibre; (B) Thickback sole (10.5 mm in length) with 270 $\mu \mathrm{m}$ rayon fibre; (C) Common dragonet (9 $\mathrm{mm}$ in length) with 2 blue nylon fibres ( $220 \mu \mathrm{m}$ and $230 \mu \mathrm{m})$. Image credit: $\mathrm{M}$ Steer.

\subsection{Waterborne microplastics in the water column}

275 We observed a trend of decreasing microplastic concentrations with distance from shore 276 (exponential regression, $P<0.01$; Figure 2B). Microplastic concentrations were highly variable, ranging $0.26-3.79 \mathrm{~m}^{-3}$ across sites, with an average microplastic concentration across all three study 
sites of 1.39 particles $\mathrm{m}^{-3}$. The microplastic debris predominantly consisted of fibres (77\%) and fragments (23\%), with no significant difference in shape between sites (ANOVA, $P=0.485$ ); Figure 4; Figure 5A). Out of a total 2772 microplastic particles observed, only one bead was identified. Across all three sites, approximately $50 \%$ of the microplastics were blue (Figure $5 \mathrm{~B})$, with black $(21.5 \%)$, clear $(10 \%)$ and red $(9.5 \%)$ plastics also well represented. Of the microplastics analysed: $63 \%$ were mixtures of plastic compounds (co-polymers) and $36 \%$ were single polymers. The majority $(55 \%)$ of analysed particles were either rayon or a rayon mix (primarily rayon with polyurethane); polyethylene, nylon and acrylic were also commonly identified, both as singular or co-polymers. We further identified a significant, exponential relationship between microplastic size and relative abundance (exponential regression, $R^{2}=0.84, P<0.05$; Figure $5 C$ ), with a trend of increasing numbers of particles with decreasing size. For size fractions between $100-500 \mu \mathrm{m}$ a relationship was less evident (Figure 5D). No significant difference in microplastic size was identified between any of the three sample sites (ANOSIM, $P=0.24$ ).

291
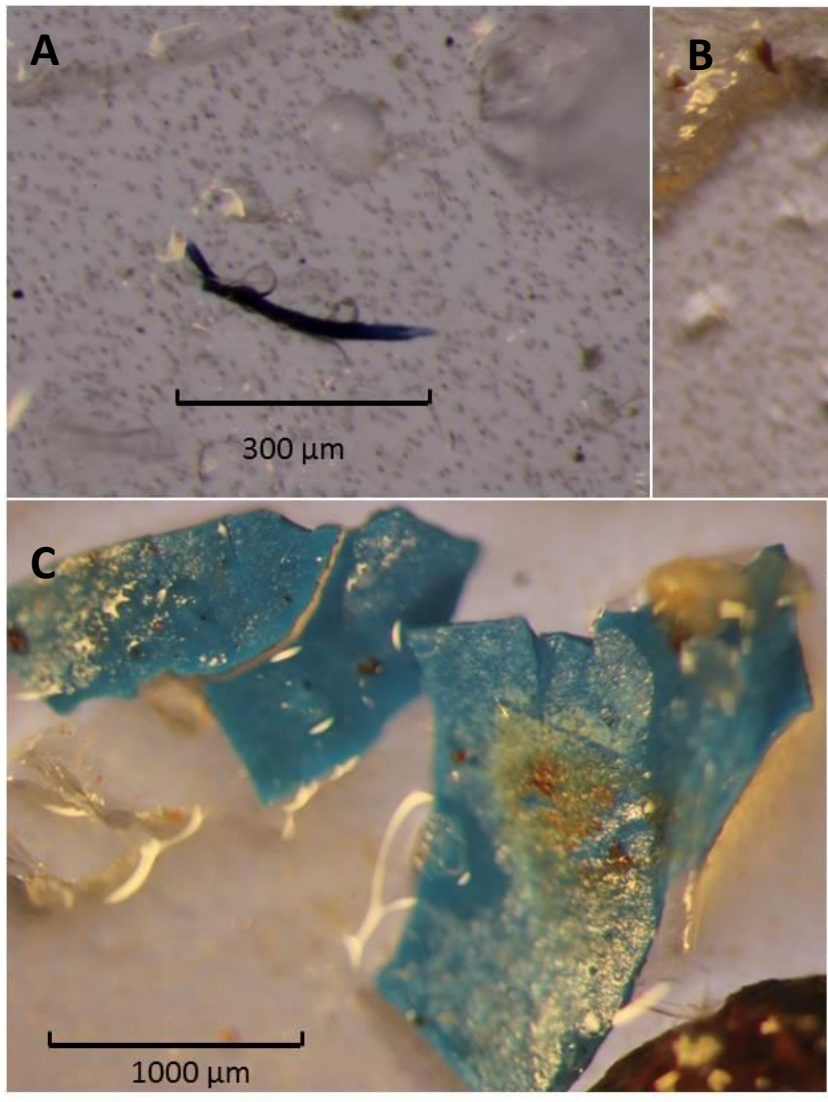

D

Figure 4. Selection of microplastics from water samples. (A) Blue fibre, $310 \mu \mathrm{m}$, rayon; (B) Red fibre, knotted (2000 $\mu \mathrm{m}$ length), polyester; (C) Blue fragments, 1100-1400 $\mu \mathrm{m}$ diameter, acrylic/polyethylene/nylon copolymer; (D) Black bead, 100 
A

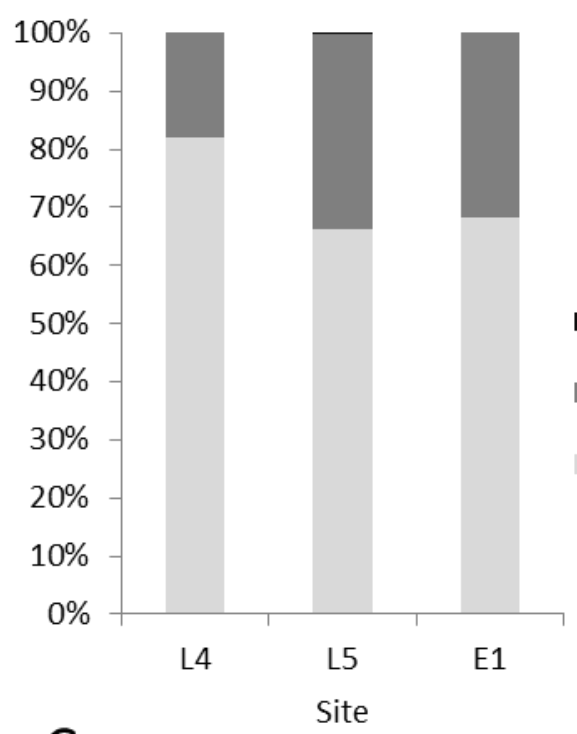

C

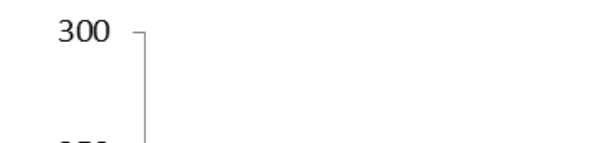

\section{D}

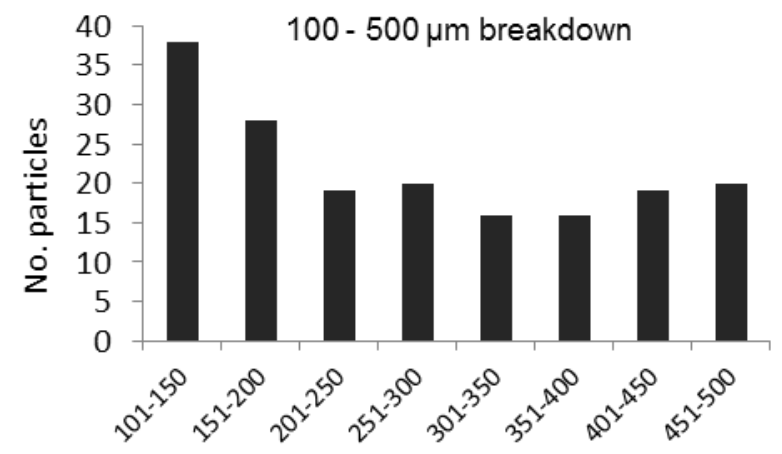

Size fraction $(\mu \mathrm{m})$

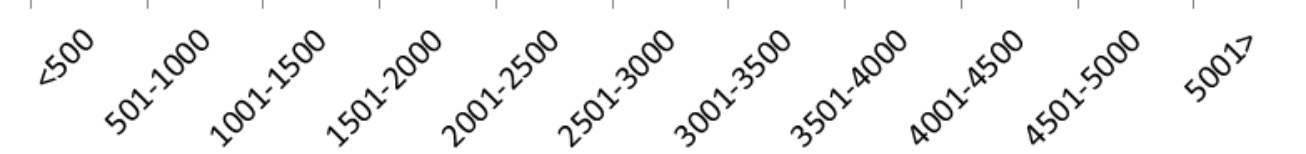

Size fraction $(\mu \mathrm{m})$

Figure 5. Waterborne microplastic debris sampled from the western English Channel. (A) Proportion (\%) of fibres, fragments and beads in water samples per site; (B) Proportional (\%) colour composition of microplastic assemblage by site; (C) Frequency distribution of size classes $(\mu \mathrm{m})$ of microplastics sampled $(n=694)$ with exponential regression $\left(R^{2}=0.84\right.$, $P=0.00, n=11$, black dotted line); (D) frequency distribution within the $100-500 \mu \mathrm{m}$ size range $(n=251)$.

\subsection{Incidence of ingestion and encounter rate}

No significant difference in 'incidence of ingestion' (Table 1; ANOVA, $n=13, P=0.24$ ) or 'encounter rate' (Table 1; ANOVA, $\mathrm{n}=13, P=0.42$ ) was observed between sites. The highest microplastic 
encounter rate (number microplastic particles ingested / number fish dissected) was at site L5 (5.28\%), closely followed by L4 (5.15\%) with E1 noticeably lower at $0.72 \%$ (Table 2; Figure 6). There was significant variance in fish larvae concentrations between sites (Figure 6; ANOVA, $P<0.05$ ), with E1 showing significantly higher fish larval numbers than at L4 and L5. No significant difference in microplastic concentrations (Figure 6; ANOVA, $\mathrm{P}=0.11$ ) was observed between sites, although a trend of decreasing concentrations with distance from the coast was noted.

When comparing fish larvae concentrations with waterborne microplastic concentrations, the site closest to Plymouth $(10 \mathrm{~km})$ had a ratio of 27 microplastic particles per single fish larvae in the water. This decreased to a 1:1 ratio at E1, $35 \mathrm{~km}$ offshore (Table 2). Although fish larvae concentrations were at their lowest at L4 station (closest proximity to Plymouth), microplastics concentrations were at their highest, accounting for the maximum value of incidence of ingestion recorded (Table 1).
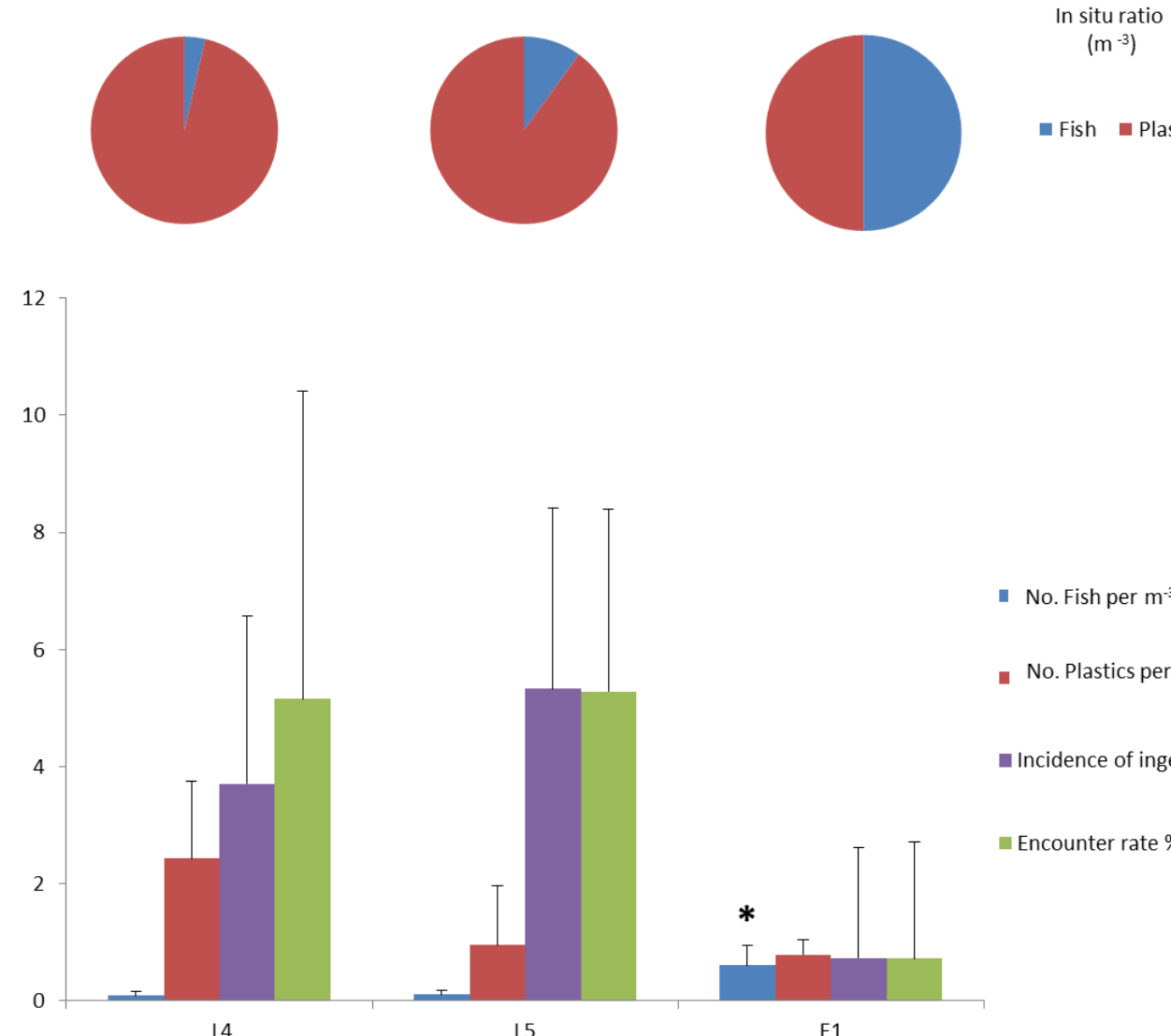

L4

L5

E1

Site

Figure 6. ABOVE: The ratio between concentration of microplastics and fish larvae in the water column at each site is displayed. BELOW: Comparison between plastic concentrations (number $\mathrm{m}^{-3}$ ), fish larvae concentrations (individuals $\mathrm{m}^{-3}$ ), incidence of ingestion (number of fish with ingested particles/ number of fish dissected) and encounter rate (number microplastic particles ingested/ number fish dissected) per site; * denotes significant difference from other sites. 


\section{Discussion}

The results demonstrate $2.9 \%$ of fish larvae found at the study sites in the western English Channel had ingested microplastics. Of the ingested particles, $83 \%$ were fibrous and $83 \%$ were blue, mirroring the assemblage of microplastics concurrently sampled from the water column. Fish larvae abundance increased with distance from shore, while waterborne microplastic concentrations decreased. At L4 and L5, within the designated $19 \mathrm{~km}$ coastal water zone (UN convention), a 5.2\% encounter rate was observed alongside a fish to microplastic ratio per cubic meter of water of 1:27 and 1:9 respectively; at E1, $35 \mathrm{~km}$ from the coast, this decreased to $0.72 \%$ and a ratio of 1:1.

\subsection{Prevalence of microplastic ingestion}

334 Exposure studies have revealed zooplankton are capable of ingesting microplastics (Cole et al., 2013), however evidence of microplastic consumption in natura is less evident. In Portuguese coastal waters $61 \%$ of zooplankton ( $n=152$, species not determined) had ingested microplastics (Frias et al., 2014). In the Northeast Pacific, calanoid copepods (Neocalanus cristatus) and euphausiids (Euphausia pacifica) exhibited a microplastic encounter rate of $2.6 \%$ and $5.8 \%$ respectively (Desforges et al., 2015). Until recently, the uptake of microplastics by meroplankton (planktonic for a single stage of life cycle) in the field has been severely understudied. Recent research on incidence of microplastic ingestion across five zooplankton groups, including fish larvae, sampled from the South China sea revealed an encounter rate of $120 \%$ (Sun et al., 2016); however, in that study sampling was limited to "several larvae", with no concurrent waterborne microplastic data recorded.

Here, we have identified that microplastics are ingested by a number of different species of fish larvae (meroplankton) in their natural environment. Fish larvae spend their entire planktonic stage in the pelagic zone and are unselective feeders. When prey concentration is low they not only pursue all prey sizes encountered but also increase their swimming activity and are much less selective (Munk and Nielson, 2005). By dissecting individual fish larvae, we were able to calculate 'incidence of ingestion', which ranged 3.2-5.5\% across sites. For comparison with other studies on zooplankton, where bulk digestions have been used to extract microplastics, we also calculated 'encounter rates'. Our analysis of fish larvae in the western English Channel has demonstrated an encounter rate with microplastics of between $0.7-5.3 \%$. At L4, 3.7\% of fish larvae ingested plastic; comparatively, $36.5 \%$ of adult fish sampled from L4 (June 2010-July 2011) had ingested microplastics (Lusher et al. (2013). Research by Rummel et al. (2016) recorded significantly higher 
fish examined in this study were approximated to be between 5 days and 2 months old, excluding the European eel elver at less than a year old (Russell, 1976); microplastics would therefore have been encountered over a considerably shorter time frame than in adult fish, which may account for the lower proportion of individuals containing plastic observed alongside potential differences in gut retention times. All of the fish species that had ingested microplastics in this study (excluding the European eel larvae) have also been identified to consume microplastics as adults (Lusher et al., 2013). Further work is required to gauge how long fish larvae will retain ingested microplastics in order to better predict the likely impact of ingestion of the individual (i.e. are ingested plastics transient or do they have long residence times).

\subsection{Potential health effects}

Very little is known regarding the effects of ingesting microplastics on wild fish. There are substantial difficulties in assessing physiological or behavioural responses to ingestion in the wild, largely due to the inability to assess gut retention times or monitor chronic health effects arising from a single stressor. Laboratory studies on fish have illustrated significant physiological (gut blockage, decrease in food intake due to less gut space) and toxicological (inflammatory responses, oxidative stress, hepatic stress, decreased energy availability) damage can result from consumption of plastics (Rochman et al., 2013b, Oliveira et al., 2013, Mazurais et al., 2015, de Sa et al., 2015, Karami et al., 2016). However, the environmental relevance of such laboratory studies are often limited. For example, we note that the concentrations and types of microplastics used in the aforementioned exposure studies are largely unrepresentative of the microplastics identified at our study sites. We advocate that microplastics used in experiments need to reflect what is found in the field more closely as this information becomes available; the use of environmentally aged fibres (i.e. with adsorbed POPs, biofilms and dimethyl sulphide (Ziccardi et al., 2016, Wardrop et al., 2016, Jang et al., 2016, Lambert et al., 2014, Savoca et al., 2016)) would give a much better understanding of the fate and effects of microplastics in the marine ecosystem. Ecologically relevant data is essential in order to address the impacts of microplastics on animal populations, communities and ecosystems.

Laboratory experiments using juvenile fish or fish larvae are currently limited in scope and number. Owing to the susceptibility of fish larvae to environmental stressors during development, it is imperative that the effects of microplastic exposure on key health parameters (i.e. growth rate, feeding) in juvenile fish is given due attention. de Sa et al. (2015) revealed that developmental conditions may influence a fish's ability to distinguish plastic from prey; it would therefore be 
intriguing to evaluate whether community fitness has a bearing on a fish larvae's ability to select prey over plastic.

The encounter rates observed in this study are relatively low when compared to previous studies on zooplankton, partly due to the fact that as larval concentrations increased, microplastic concentrations decreased (with distance from shore). We would expect that higher encounter rates would be observed where high microplastic concentrations overlap with high fish larval concentrations; in these instances, we might reasonably expect that negative health effects on individuals could extend to the population as a whole. Fish produce high numbers of eggs in order to account for the high mortality rates in larvae, therefore the relationship between larval survival and population dynamics is complex.

\subsection{Comparison between waterborne and ingested microplastics}

The characteristics of the microplastics ingested by fish larvae were representative of those found in the water column, with 8 blue fibres out of 12 particles, reflecting the $77 \%$ fibre and $50 \%$ blue composition of the microplastics in the water. Desforges et al. (2015) also found fibrous microplastics were predominant in euphausiids (68\% fibres) and copepods (50\% fibres). Black microplastics accounted for $21.5 \%$ of the water samples in this study whilst red just $9.5 \%$, however red fibres constituted $17 \%$ of the ingested particles whereas black wasn't ingested at all. If we are to successfully advise on policy for microplastic production, use and disposal, it is advisable that future laboratory experiments also assess the possibility of feeding selectivity taking place on microplastic colour and shape.

Constituting over $50 \%$ of the microplastics found in our water samples, Rayon is a semi synthetic bioplastic used in clothing, furnishing, female hygiene products and nappies; Cole (2014) also found Rayon in the surface waters at L4 and close to the Plymouth sound (October 2013). Bioplastics (i.e. Rayon) are rarely represented in toxicity testing of microplastics, and should be considered an area requiring further testing. The large number of microscopic synthetic fibres found in the water suggests sewage outlets might be a prominent source of microplastic pollution observed across our sampling sites (Browne et al., 2010). Polyester and polyurethane (PU) were also identified in the waterborne samples; both polymers are used in resin systems for boat hulls, PU is found in numerous marine paints and polyester is a popular material for commercial marine rope including fishing nets in conjunction with nylon. There was a notable absence of microbeads in our samples, however this may be an artefact of our sampling protocol: Fendall and Sewell (2009) report that two 
thirds of cosmetic brands use $<100 \mu \mathrm{m}$ microbeads, therefore in using a $100 \mu \mathrm{m}$ net we would be unlikely to capture spherical particles below this size threshold. The most abundant size range of waterborne microplastics was the $<500 \mu \mathrm{m}$ category, with abundance decreasing exponentially as particle size increased; a trend also reported in open ocean samples by Cozar et al. (2014). These plastics are of a similar size to microzooplankton which form a key component of the diet of fish larvae.

\subsection{Relationship between distance and uptake}

Shelf-sea ecosystems have been highlighted as regions with high likelihood of microplastic-biotic interaction. In coastal regions close to urban centres (e.g. Plymouth) microplastic concentrations will be higher owing to their proximity to a source of input. Likewise, biological productivity is higher in shelf-seas because of increased nutrient and organic carbon input from land (Clark et al., 2016). Our data concurs with this hypothesis, showing a microplastic encounter rate of $5.2 \%$ in fish larvae within $19 \mathrm{~km}$ of shore, while fish larvae $35 \mathrm{~km}$ from shore encountered far less $(0.72 \%)$. We observed a decrease in waterborne microplastic concentrations with increasing distance from the coastline. The high degree of temporal variability in the L4 microplastic assemblage (standard deviation for $L 4=1.26, L 5=0.97, E 1=0.24$ ) could be accounted for by its proximity to Plymouth and the variations in input which can fluctuate depending on runoff, tidal regime, sewage input, weather and pollution incidents. Furthermore there is the possibility of seasonal variability in the transport of microplastics from Plymouth sound out to sea. Only a fraction of the particles released from the sound are likely to reach L4 - instead they are swept westward close to the coastline (J Clark, Plymouth Marine Laboratory, personal comms). This could account for the decreased microplastic concentrations experienced with increased distance from shore; alongside a dilution effect. The observed homogeneity in colour and shape of particles across all three sites suggests consistent sources of contamination (i.e. sewage outfall, maritime activity); however this isn't necessarily from a geographically similar source. E1 has oceanic water influence therefore it is perhaps unlikely that large numbers of microplastics from a source in Plymouth would reach the site. Similar sources of microplastic contamination (i.e. sewage, maritime and industrial) exist along the south coast of England and it is these inputs that are more likely to be the key influence on the assemblage of plastics outside of the coastal zone.

The abundance of fish larvae increased with increasing distance from shore. This study targeted spring spawning boreal species residing throughout the water column and at their most abundant and diverse in May (Russell, 1976). Fish larvae remain planktonic until adolescence when they move 
to their preferred habitat (e.g. Gadoids to rocky shores, flatfish to the benthos). Until this time they remain planktonic and in deeper water, with only surface dwelling larvae prone to onshore drift by prevailing winds; thus explaining the lower numbers recorded close to shore. Conversely microplastic concentrations decreased with distance from shore and as such, the ratio of fish:plastic decreased and directly correlated with the frequency of microplastic consumption. It is generally hypothesised that biota in coastal regions will experience a greater impact from microplastic ingestion. Furthermore we suggest that spatial and temporal overlap is key to the degree of impact observed at population level. Microplastic concentrations are spatially and temporally variable, influenced by local currents, accumulation spots and climate events among others. If these hotspots overlie spawning grounds for adult fish and areas where planktonic larvae fish are abundant then there will be far greater incidence of ingestion and therefore significantly higher encounter rate observed than during this study. It is the identification of these areas alongside a drive towards to producing ecologically relevant data that should be the focus of future research efforts in order to target prevention, policy and legislation (Rochman, 2016). The emphasis should now be on encouraging the use of preventative measures rather than the need for expensive clean-up operations.

\section{Conclusion}

Although the observed ingestion rate for microplastics in fish larvae was low at $2.9 \%$ we must remember that these meroplankton have in fact only been in the pelagic zone as plankton for a matter of weeks. Based upon the existing evidence, we suggest that ingestion of microplastics is likely to be detrimental to these individuals, however it is currently unclear whether the low incidence of ingestion would be sufficient to contribute to negative impacts at the population level. There are difficulties in assessing the pattern of ingestion due to the low number of individuals found to contain microplastic; further investigtation is required to determine whether fish larvae exhibit selective behaviour towards microplastics of differing shape and colour. Concurrent water sampling allowed an invaluable insight into the microplastic assemblage in the water at the time of ingestion; this novel data highlights the spatial and temporal overlap of larvae and microplastics. There can be no doubt that zooplankon, including merplankton, are ingesting microplastics and biomicroplastics. This study has shown that higher encounter rates occur where microplastic concentrations exceed those of fish larvae. We therefore expect incidence of ingestion to be greatest in productive habitats which experience high concentrations of microplastics. 
Acknowledgements.

495

496

497

498

499

500

501

502

503

504

505

506

507

508

509

510

511

512

513

514

515

516

517

518

519

520

521

522

523

524

525

526

We would like to thank the captain and crew of RV Plymouth Quest, Nick Halliday at the Marine Biological Association for guidance with larval indentification and Andrew Tonkin at Plymouth Univeristy for instruction on the use of FT-IR. PKL and MC are funded by the Natural Environment Research Council (grant NE/L007010).

\section{References.}

A History of Plastics, British Plastics Federation. Available at http://www.bpf.co.uk/plastipedia/plastics_history/default.aspx. (Accessed 07 March 2017).

Andrady, Anthony L. "Persistence of plastic litter in the oceans." Marine anthropogenic litter. Springer International Publishing, 2015. 57-72.

Baran, E., "The importance of non-commercial fish", UNESCO Encyclopedia Of Life Support Systems (theme «Fisheries and Aquaculture»), Chap. 5.5.2.11, 2002.

Braid, H. E., Deeds, J., Degrasse, S. L., Wilson, J. J., Osborne, J. \& Hanner, R. H. 2012. Preying on commercial fisheries and accumulating paralytic shellfish toxins: a dietary analysis of invasive Dosidicus gigas (Cephalopoda Ommastrephidae) stranded in Pacific Canada. Marine Biology, 159, 25 31.

Browne, M. A., Crump, P., Niven, S. J., Teuten, E., Tonkin, A., Galloway, T. \& Thompson, R. 2011. Accumulation of Microplastic on Shorelines Woldwide: Sources and Sinks. Environmental Science \& Technology, 45, 9175-9179.

Browne, M. A., Galloway, T. S. \& Thompson, R. C. 2010. Spatial Patterns of Plastic Debris along Estuarine Shorelines. Environmental Science \& Technology, 44, 3404-3409.

Carpenter, E.J., Anderson, S. J., Miklas, H. P., Peck, B. B. \& Harvey, G. R. 1972. Polystyrene Spherules In Coastal Waters. Science, 178, 749-\&.

Clark, J. R., Cole, M., Lindeque, P. K., Fileman, E., Blackford, J., Lewis, C., Lenton, T. M. \& Galloway, T. S. 2016. Marine microplastic debris: a targeted plan for understanding and quantifying interactions with marine life. Frontiers in Ecology and the Environment, 14, 317-324.

Cole, M. \& Galloway, T. S. 2015. Ingestion of Nanoplastics and Microplastics by Pacific Oyster Larvae. Environmental Science \& Technology, 49, 14625-14632.

Cole, M., Lindeque, P., Fileman, E., Halsband, C. \& Galloway, T. S. 2015. The Impact of Polystyrene Microplastics on Feeding, Function and Fecundity in the Marine Copepod Calanus helgolandicus. Environmental Science \& Technology, 49, 1130-1137.

Cole, M., Lindeque, P., Fileman, E., Halsband, C., Goodhead, R., Moger, J. \& Galloway, T. S. 2013. Microplastic Ingestion by Zooplankton. Environmental Science \& Technology, 47, 6646-6655. 
540 Cole, M., Lindeque, P., Halsband, C. \& Galloway, T. S. 2011. Microplastics as contaminants in

541 the marine environment: A review. Marine Pollution Bulletin, 62, 2588-2597.

542 Cole, M., Webb, H., Lindeque, P. K., Fileman, E. S., Halsband, C. \& Galloway, T. S. 2014.

Cozar, A., Echevarria, F., Ignacio Gonzalez-Gordillo, J., Irigoien, X., Ubeda, B., Hernandez-Leon, S., Palma, A. T., Navarro, S., Garcia-De-Lomas, J., Ruiz, A., Fernandez-DePuelles, M. L. \& Duarte, C. M. 2014. Plastic debris in the open ocean. Proceedings of the National Academy of Sciences of the United States of America, 111, 10239-10244.

De Sa, L. C., Luis, L. G. \& Guilhermino, L. 2015. Effects of microplastics on juveniles of the common goby (Pomatoschistus microps): Confusion with prey, reduction of the predatory performance and efficiency, and possible influence of developmental conditions. Environmental Pollution, 196, 359 362.

Desforges, J.-P. W., Galbraith, M., Dangerfield, N. \& Ross, P. S. 2014. Widespread distribution of microplastics in subsurface seawater in the NE Pacific Ocean. Marine Pollution Bulletin, 79, 94-99.

Desforges, J.-P. W., Galbraith, M. \& Ross, P. S. 2015. Ingestion of Microplastics by Zooplankton in the Northeast Pacific Ocean. Archives of Environmental Contamination and Toxicology, 69, 320 330.

Devriese, L. I., Van Der Meulen, M. D., Maes, T., Bekaert, K., Paul-Pont, I., Frere, L., Robbens, J. \& Vethaak, A. D. 2015. Microplastic contamination in brown shrimp (Crangon crangon, Linnaeus 1758) from coastal waters of the Southern North Sea and Channel area. Marine Pollution Bulletin, 98, 179-187.

Enders, K., Lenz, R., Stedmon, C. A. \& Nielsen, T. G. 2015. Abundance, size and polymer composition of marine microplastics $>=10 \mathrm{mu} \mathrm{m}$ in the Atlantic Ocean and their modelled vertical distribution. Marine Pollution Bulletin, 100, 70-81.

Eriksen, M., Lebreton, L. C. M., Carson, H. S., Thiel, M., Moore, C. J., Borerro, J. C., Galgani, F., Ryan, P. G. \& Reisser, J. 2014. Plastic Pollution in the World's Oceans: More than 5 Trillion Plastic Pieces Weighing over 250,000 Tons Afloat at Sea. Plos One, 9.

Fendall, L. S. \& Sewell, M. A. 2009. Contributing to marine pollution by washing your face: Microplastics in facial cleansers. Marine Pollution Bulletin, 58, 1225-1228.

Frias, J. P. G. L., Otero, V. \& Sobral, P. 2014. Evidence of microplastics in samples of zooplankton from Portuguese coastal waters. Marine Environmental Research, 95, 89-95.

Galloway, Tamara S. "Micro-and nano-plastics and human health." Marine anthropogenic litter. Springer International Publishing, 2015. 343-366.

History of Plastics, 2016. Available at: http://www.plasticseurope.org/what-is-plastic/history.aspx. (Accessed 04 January 2017).

Goldstein, M. C. \& Goodwin, D. S. 2013. Gooseneck barnacles (Lepas spp.) ingest microplastic debris in the North Pacific Subtropical Gyre. Peerj, 1. 
Jambeck, J. R., Geyer, R., Wilcox, C., Siegler, T. R., Perryman, M., Andrady, A., Narayan, R. \& Law, K. L. 2015. Plastic waste inputs from land into the ocean. Science, 347, 768-771.

Jang, M., Shim, W. J., Han, G. M., Rani, M., Song, Y. K. \& Hong, S. H. 2016. Styrofoam Debris as a Source of Hazardous Additives for Marine Organisms. Environmental Science \& Technology, 50, 4951-4960.

Kaposi, K. L., Mos, B., Kelaher, B. P. \& Dworjanyn, S. A. 2014. Ingestion of Microplastic Has Limited Impact on a Marine Larva. Environmental Science \& Technology, 48, 1638-1645.

Karami, A., Romano, N., Galloway, T. \& Hamzah, H. 2016. Virgin microplastics cause toxicity and modulate the impacts of phenanthrene on biomarker responses in African catfish (Clarias gariepinus). Environmental Research, 151, 58-70.

Lam, V. W. Y., Cheung, W. W. L., Reygondeau, G. \& Sumaila, U. R. 2016. Projected change in global fisheries revenues under climate change. Scientific Reports, 6, 32607.

Lambert, S., Sinclair, C. \& Boxall, A. 2014. Occurrence, Degradation, and Effect of Polymer-Based Materials in the Environment. In: WHITACRE, D. M. (ed.) Reviews of Environmental Contamination and Toxicology, Vol 227.

Lee, K. W., Shim, W. J., Kwon, O. Y. \& Kang, J. H. 2013. Size-Dependent Effects of Micro Polystyrene Particles in the Marine Copepod Tigriopus japonicus. Environmental Science \& Technology, 47, 11278-11283.

Lusher, Amy. "Microplastics in the marine environment: distribution, interactions and effects." Marine anthropogenic litter. Springer International Publishing, 2015. 245-307.

Lusher, A., Welden, N., Sobral, P. \& Cole, M. 2017. Sampling, isolating and identifying microplastics ingested by fish and invertebrates. Analytical Methods.

Lusher, A. L., Mchugh, M. \& Thompson, R. C. 2013. Occurrence of microplastics in the gastrointestinal tract of pelagic and demersal fish from the English Channel. Marine Pollution Bulletin, 67, 94-99.

Lusher, A. L., Tirelli, V., O'connor, I. \& Officer, R. 2015. Microplastics in Arctic polar waters: the first reported values of particles in surface and sub-surface samples. Scientific Reports, 5.

Mazurais, D., Ernande, B., Quazuguel, P., Severe, A., Huelvan, C., Madec, L., Mouchel, O., Soudant, P., Robbens, J., Huvet, A. \& Zambonino-Infante, J. 2015. Evaluation of the impact of polyethylene microbeads ingestion in European sea bass (Dicentrarchus labrax) larvae. Marine environmental research, 112, 78-85.

Murray, F. \& Cowie, P. R. 2011. Plastic contamination in the decapod crustacean Nephrops norvegicus (Linnaeus, 1758). Marine Pollution Bulletin, 62, 1207-1217.

Napper, I. E., Bakir, A., Rowland, S. J. \& Thompson, R. C. 2015. Characterisation, quantity and sorptive properties of microplastics extracted from cosmetics. Marine Pollution Bulletin, 99, 178-185.

Nobre, C. R., Santana, M. F. M., Maluf, A., Cortez, F. S., Cesar, A., Pereira, C. D. S. \& Turra, A. 2015. Assessment of microplastic toxicity to embryonic development of the sea urchin Lytechinus 
variegatus (Echinodermata: Echinoidea). Marine Pollution Bulletin, 92, 99-104.

Norén, F. 2007. Small plastic particles in coastal Swedish waters. KIMO Sweden. Ogonowski, M., Schur, C., Jarsen, A. \& Gorokhova, E. 2016. The Effects of Natural and Anthropogenic Microparticles on Individual Fitness in Daphnia magna. Plos One, 11.

Oliveira, M., Ribeiro, A., Hylland, K. \& Guilhermino, L. 2013. Single and combined effects of microplastics and pyrene on juveniles (0+group) of the common goby Pomatoschistus microps (Teleostei, Gobiidae). Ecological Indicators, 34, 641-647.

Peda, C., Caccamo, L., Fossi, M. C., Gai, F., Andaloro, F., Genovese, L., Perdichizzi, A., Romeo, T. \& Maricchiolo, G. 2016. Intestinal alterations in European sea bass Dicentrarchus labrax (Linnaeus, 1758) exposed to microplastics: Preliminary results. Environmental Pollution, 212, 251 256.

Rebolledo, E. L. B., Van Franeker, J. A., Jansen, O. E. \& Brasseur, S. M. J. M. 2013. Plastic ingestion by harbour seals (Phoca vitulina) in The Netherlands. Marine Pollution Bulletin, 67, 200 202.

Rochman, C. M. 2016. Ecologically relevant data are policy-relevant data. Science, 352, 1172-1172.

Rochman, C. M., Browne, M. A., Halpern, B. S., Hentschel, B. T., Hoh, E., Karapanagioti, H. K., Rios-Mendoza, L. M., Takada, H., Teh, S. \& Thompson, R. C. 2013a. Policy: Classify plastic waste as hazardous. Nature, 494, 169-171.

Rochman, C. M., Hoh, E., Kurobe, T. \& Teh, S. J. 2013b. Ingested plastic transfers hazardous chemicals to fish and induces hepatic stress. Scientific Reports, 3.

Rummel, C. D., Loder, M. G. J., Fricke, N. F., Lang, T., Griebeler, E. M., Janke, M. \& Gerdts, G. 2016. Plastic ingestion by pelagic and demersal fish from the North Sea and Baltic Sea. Marine Pollution Bulletin, 102, 134-141.

Savoca, M. S., Wohlfeil, M. E., Ebeler, S. E. \& Nevitt, G. A. 2016. Marine plastic debris emits a keystone infochemical for olfactory foraging seabirds. Science Advances, 2.

Setala, O., Fleming-Lehtinen, V. \& Lehtiniemi, M. 2014. Ingestion and transfer of microplastics in the planktonic food web. Environmental Pollution, 185, 77-83.

Southward, A. J., 1970. Improved Methods Of Sampling Post-Larval Young Fish And Macroplankton. Journal of the Marine Biological Association of the United Kingdom, 50, 689-\&.

Sun, X., Li, Q., Zhu, M., Liang, J., Zheng, S. \& Zhao, Y. 2016. Ingestion of microplastics by natural zooplankton groups in the northern South China Sea. Marine Pollution Bulletin.

Thompson, R. C., Olsen, Y., Mitchell, R. P., Davis, A., Rowland, S. J., John, A. W. G., Mcgonigle, D. \& Russell, A. E. 2004. Lost at Sea: Where Is All the Plastic? Science, 304, 838-838.

Tourinho, P. S., Ivar Do Sul, J. A. \& Fillrnann, G. 2010. Is marine debris ingestion still a problem for the coastal marine biota of southern Brazil? Marine Pollution Bulletin, 60, 396-401. 
691

692

693

694

695

696

697

698

699

700

701

702

703

704

705

706

707

708

709

710

711

712

713

714

715

716

717

718

719

720

UNESCO, 1968. Zooplankton Sampling. Monographs on Oceanographic Methodology. Unesco, Paris, $174 \mathrm{pp}$.

Van Cauwenberghe, L. \& Janssen, C. R. 2014. Microplastics in bivalves cultured for human consumption. Environmental Pollution, 193, 65-70.

Van Cauwenberghe, L., Vanreusel, A., Mees, J. \& Janssen, C. R. 2013. Microplastic pollution in deep-sea sediments. Environmental Pollution, 182, 495-499.

Wardrop, P., Shimeta, J., Nugegoda, D., Morrison, P. D., Miranda, A., Tang, M. \& Clarke, B. O. 2016. Chemical Pollutants Sorbed to Ingested Microbeads from Personal Care Products Accumulate in Fish. Environmental Science \& Technology, 50, 4037-4044.

Watts, A. J. R., Urbina, M. A., Goodhead, R., Moger, J., Lewis, C. \& Galloway, T. S. 2016. Effect of Microplastic on the Gills of the Shore Crab Carcinus maenas. Environmental Science \& Technology, 50, 5364-5369.

Worm, B., Barbier, E. B., Beaumont, N., Duffy, J. E., Folke, C., Halpern, B. S., Jackson, J. B. C., Lotze, H. K., Micheli, F., Palumbi, S. R., Sala, E., Selkoe, K. A., Stachowicz, J. J. \& Watson, R. 2006. Impacts of Biodiversity Loss on Ocean Ecosystem Services. Science, 314, 787-790.

Wright, S. L., Rowe, D., Thompson, R. C. \& Galloway, T. S. 2013a. Microplastic ingestion decreases energy reserves in marine worms. Current Biology, 23, R1031-R1033.

Wright, S. L., Thompson, R. C. \& Galloway, T. S. 2013b. The physical impacts of microplastics on marine organisms: A review. Environmental Pollution, 178, 483-492.

Ziccardi, L. M., Edgington, A., Hentz, K., Kulacki, K. J. \& Driscoll, S. K. 2016. Microplastics as vectors for bioaccumulation of hydrophobic organic chemicals in the marine environment: A state of-thescience review. Environmental Toxicology and Chemistry, 35, 1667-1676. 